\title{
Pfeiffer syndrome type 2
}

INSERM

\section{Source}

INSERM. (1999). Orphanet: an online rare disease and orphan drug data base. Pfeiffer syndrome type 2. ORPHA:93259

Pfeiffer syndrome type 2 (PS2) is a frequent and severe type of Pfeiffer syndrome (PS; see this term), characterized by cloverleaf skull, severe associated functional disorders, and hand/foot and elbow/knee abnormalities. 